\title{
Correlation of Stereoselectivity and Ion Response in Electrospray Mass-Spectrometry. Electrospray Ionization-Mass Spectrometry as a Tool to Predict Chemical Behavior?
}

\author{
Alexander Chapeaurouge, ${ }^{*}$ Laurent Bigler, ${ }^{*}$ Andrea Schäfer, and \\ Stefan Bienz \\ Organisch-chemisches Institut, Universität Zürich, Winterthurerstrasse 190, CH-8057 Zürich, Switzerland
}

\begin{abstract}
Several alkali cation complexes of chiral alkoxymethyl-substituted acylsilanes, prepared in situ by the admixture of alkali iodides to acylsilane sample solutions, were investigated by electrospray ionization-mass spectrometry. Competition experiments suggest that the relative complex stabilities of such species in acetonitrile solution follow the order $S_{\left[M+L_{i}\right]}<$ $S_{[M+N a]^{+}}>S_{[M+K]^{+}}$, which is different from the order of the relative stabilities of the complexes in the gas phase $\left(S_{[M+L i]}>S_{[M+N a]} \cdot>S_{[M+K]}\right.$. $)$ as qualitatively determined by a tandem mass spectrometry-type experiment. Additionally, a rough correlation of relative ion responses in the mass spectrometry with relative stereoselectivities-derived from chelatecontrolled reactions performed with the respective silanes-was found. The latter observation suggests that the electrospray ionization-mass spectrometry technique is a potentially useful method to predict chemical behavior, and it demands little experimental effort. (J Am Soc Mass Spectrom 1995, 6, 207-211)
\end{abstract}

$\mathrm{E}$ lectrospray ionization (ESI)-like the related ion spray ionization [1-3] or electrohydrodynamic dionization [4]-is a technique that allows the formation of charged particles amenable to mass spectrometry by desolvation of ions from liquids of low viscosity and low surface tension [5-13]. To form the gaseous ions out of the liquid phase a sample solution is sprayed into the gas phase by a capillary that has an electric field applied to its end. Because charged droplets are formed under such conditions it is assumed that mechanisms of field-induced ion evaporation as discussed by Iribarne [14] and Thomson [15, 16] or of electrohydrodynamic disintegration of the droplets under field stress as favored by Röllgen and co-workers $[6,10,17,18]$ play important roles in ion formation. Independent of the formation mechanism, it is in any case proposed that the typically observed molecular ions, such as $[\mathrm{M}+\mathrm{H}]^{+},[\mathrm{M}+\mathrm{Na}]^{+},[\mathrm{M}+$ $\left.\mathrm{NH}_{4}\right]^{+}$, and $[\mathrm{M}-\mathrm{H}]^{-}$, are already formed in solution by proton, sodium, and ammonium attachment to the substrate or proton abstraction from the sample compound, respectively. In 1992 it was shown that a qualitative or semiquantitative correlation between

Address reprint requests to Dr. Stefan Bienz, Organisch-chemisches Institut, Universität Zürich, Winterthurerstrasse $190, \mathrm{CH}-8057 \mathrm{Zürich,}$ Switzerland.

*This work is part of the planned Ph.D. thesis of A.C. and L.B., University of Zurich. electrospray response and calculated equilibrium concentrations of different species in aqueous solution can be observed $[19,20]$. Even quantitative correlations were found when ions of identical charge and similar type were compared.

This observed correlation of electrospray ionizationmass spectrometry (ESI-MS) ion responses with the respective particle concentrations in solution implies the possibility to determine qualitatively or even quantitatively relative complex stabilities of components in thermodynamically unknown systems by simple ESIMS experiments. Our initial interest in the investigation of such "unknown" systems was focused on the determination of relative ion responses that are derived from different cationic alkali metal complexes with the acylsilanes $1 \mathbf{a}-\mathbf{d}$ [i.e., chelates of the type $\mathbf{A}$ (scheme in Table 1)]. Because we proposed a "chelatecontrolled" reaction path via closely related complexes of the type $\mathbf{A}^{\prime}$ to be responsible for the substantial diastereoselectivities obtained in the additions of organometallic compounds to the chiral alkoxymethylsubstituted acylsilanes 1a-d [21], we expected to find a correlation of relative ion responses of metal complexes of these compounds in ESI-MS with the relative degrees of stereoselectivity [expressed, for example, as diastereoisomeric excesses (de); see Table 1] observed in the formation of addition products (e.g., of $\mathbf{2 a}-\mathbf{d}$ ). If such a correlation were found, the ESI-MS possibly 
could be used as a rather simple method to predict chemical behavior based on complexation properties.

In this communication we present the results of an ESI-MS investigation of the four compounds $1 \mathrm{a}-\mathrm{d}$, and we discuss the scope and limitations of the correlation of mass spectrometric and "wet-chemical" results.

\section{Experimental}

\section{Materials}

The sample compounds were synthesized in our laboratories [21] and characterized by ${ }^{1} \mathrm{H}$ NMR, ${ }^{13} \mathrm{C} N \mathrm{NMR}$, infrared, chemical ionization-mass spectrometry, and elemental analysis. No impurities were detected by these methods. The alkali salts ( $\mathrm{LiI}, \mathrm{NaI}$, and $\mathrm{KI}$ ) were highest quality and were purchased from Fluka ( 9470 Buchs, Switzerland). The sample solutions $(0.1 \mathrm{~mm}$ in the acylsilanes and, where applicable, $10 \mathrm{~mm}$ in the alkali salts or $\mathrm{CF}_{3} \mathrm{CO}_{2} \mathrm{H}$ ) were prepared in methanol or acetonitrile (high performance liquid chromatographygrade, from Scharlon, Spain). The hundred-fold excess of salts was necessary to minimize the impurity effect from the ubiquitous $\mathrm{Na}^{+}$cations.

\section{Mass Spectrometry}

The ESI mass spectra were obtained on a Finnigan TSQ 700 triple quadrupole mass spectrometer (FinniganMAT, San Jose, CA). Samples were continuously introduced through the electrospray interface (nitrogen drying gas at $110^{\circ} \mathrm{C}$ ) at a rate of $2 \mu \mathrm{L} / \mathrm{min}$ via biasing the electrospray probe to a voltage of $3.0-3.2 \mathrm{kV}$. The ions were detected by scanning the third quadrupole, and the scans were monitored in the range of $m / z$ 200-800 (comparison of the complexes with different cations) or of $m / z$ 200-650 (comparison of complexes of different acylsilanes) in $3 \mathrm{~s}$. Between 15 and 20 scans were averaged to obtain representative spectra. The abundances of the ions are reported as percentages relative to the peak that was most intense.

The lens and quadrupole voltages were optimized to maximum ion current for electrospray (= normal conditions). For the complex dissociation experiment (tandem mass spectrometry-type experiment), the voltage at the tube lens (i.e., the focusing lens placed directly after the capillary; L41 or ESTL for the Finnigan TSQ 700) was increased by $100 \mathrm{~V}$.

\section{Results and Discussion}

\section{Electrospray Mass Spectrometry of the Acylsilanes $1 a-d$}

We started our study with the mass spectrometric investigation of the individual acylsilanes $1 a-d$ introduced via electrospray ionization. The four compounds exhibit under several conditions almost identical behavior in ESI-MS. The spectra of the compounds introduced into the mass spectrometer dissolved in pure methanol (a typical spectrum of the series is shown with that of acetylsilane 1a in Figure 1a) exhibited base peak responses of the respective $[\mathrm{M}+\mathrm{Na}]^{+}$ molecular ions together with cluster ions that corresponded by mass to the respective $[2 \mathrm{M}+\mathrm{Na}]^{+}$particles. As a consequence of the ubiquitous sodium ions, the $[\mathrm{M}+\mathrm{Na}]^{+}$ions commonly are observed with fairly well complexing substrates, even when the highest qualities of solvents are used. The observation of cluster ions of type $[2 \mathrm{M}+\mathrm{Na}]^{+}$, however, indicates that especially well complexing substrates are under investigation. The formation of species of type $[2 \mathrm{M}+\mathrm{Na}]^{+}$ was found to increase by addition of sodium iodide to the sample solution: however, in addition to the more abundant $[2 \mathrm{M}+\mathrm{Na}]^{+}$cluster ions (relative to the $[\mathrm{M}$ $+\mathrm{Na}]^{+}$species), more complex clusters of the type $[2 \mathrm{M}+\mathrm{NaI}+\mathrm{Na}]^{+}$were recorded as well (Figure $1 \mathrm{~b}$ ). With the admixture of LiI or $\mathrm{KI}$ in place of $\mathrm{NaI}$ to the sample solution, similar spectra with similar ion distributions (the ions contain lithium or potassium instead of sodium) were obtained. On the other hand, the spectra were altered strongly by the addition of trifluoroacetic acid instead of salts, and exhibited exclusively the $[\mathrm{M}+\mathrm{H}]^{+}$molecular ions.

It is noteworthy to mention at this point that the observation of gas-phase ion clusters of the type [2M

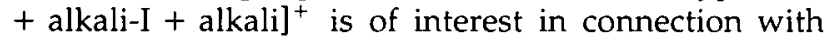
the controversy concerning the proposed electrospray ionization mechanisms. If the Röllgen mechanism of electrohydrodynamic disintegration of the droplets under field stress were operative, one would expect

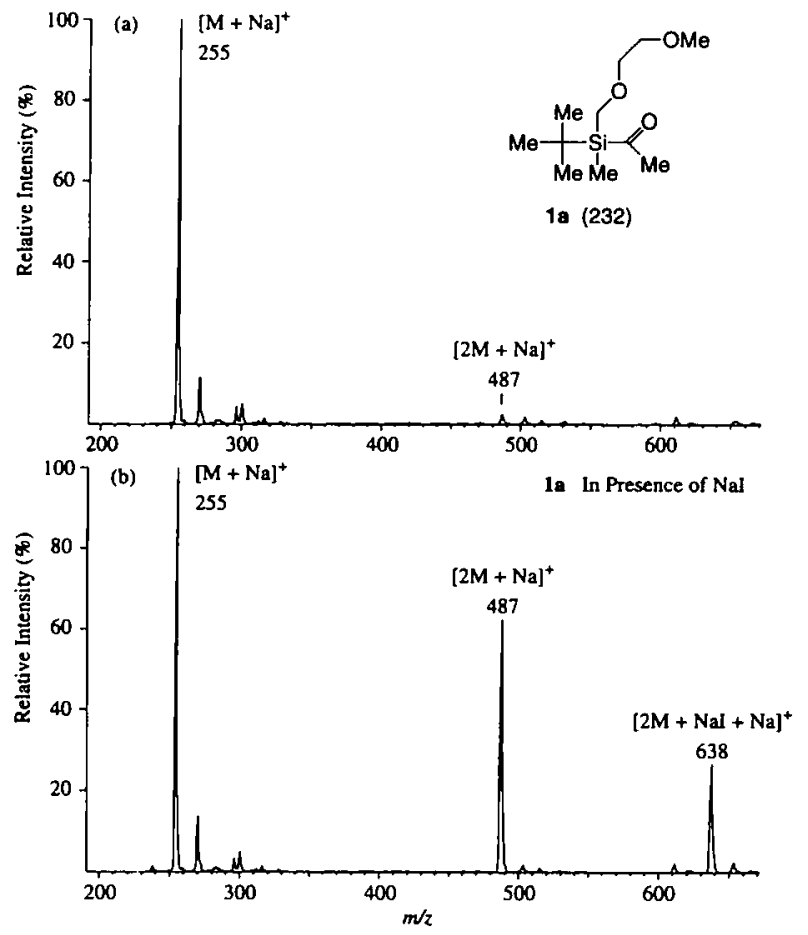

Figure 1. ESI mass spectra of $1 \mathrm{a}(0.1 \mathrm{~mm})$ applied (a) in pure methanol and (b) in 10-mM NaI/methanol. 
(according to Ikonomou et al. [9]) to detect ion clusters that contain one ion and one (or several) paired electrolyte ions in ESI-MS, which is exactly what was observed for the $[2 \mathrm{M}+\mathrm{NaI}+\mathrm{Na}]^{+}$ions, for example.

\section{Relative Stabilities of Acylsilane Alkali Complexes with Different Alkali Cations}

To determine the relative stabilities of the acylsilane complexes of, for example, 1b with lithium, sodium, and potassium cations, a competition experiment that offers the acylsilane all three cations in equimolar amounts was performed and an ion distribution [M + $\mathrm{Li}]^{+} /[\mathrm{M}+\mathrm{Na}]^{+} /[\mathrm{M}+\mathrm{K}]^{+}$of approximately 65:100:82 was obtained (Figure 2a). This ion distribution might in fact represent the relative concentrations of the respective species in methanolic solution. The relative concentrations, however, certainly do not correspond to the relative alkali ion affinities of the organic molecules in the gas phase, which are expected to decrease for the different metals in the order $\mathrm{Li}^{+}>$ $\mathrm{Na}^{+}>\mathrm{K}^{+}$. In addition to the energy terms that are derived from complexation of the cations by the acylsilane, rather large contributions to the overall energetics of the equilibrium reaction (e.g., from partial or complete solvation-desolvation of the several particles involved in the equilibrium) are important for the distribution of the species in solution as well. The relative alkali ion affinities of $\mathbf{1 b}$ should be qualita-

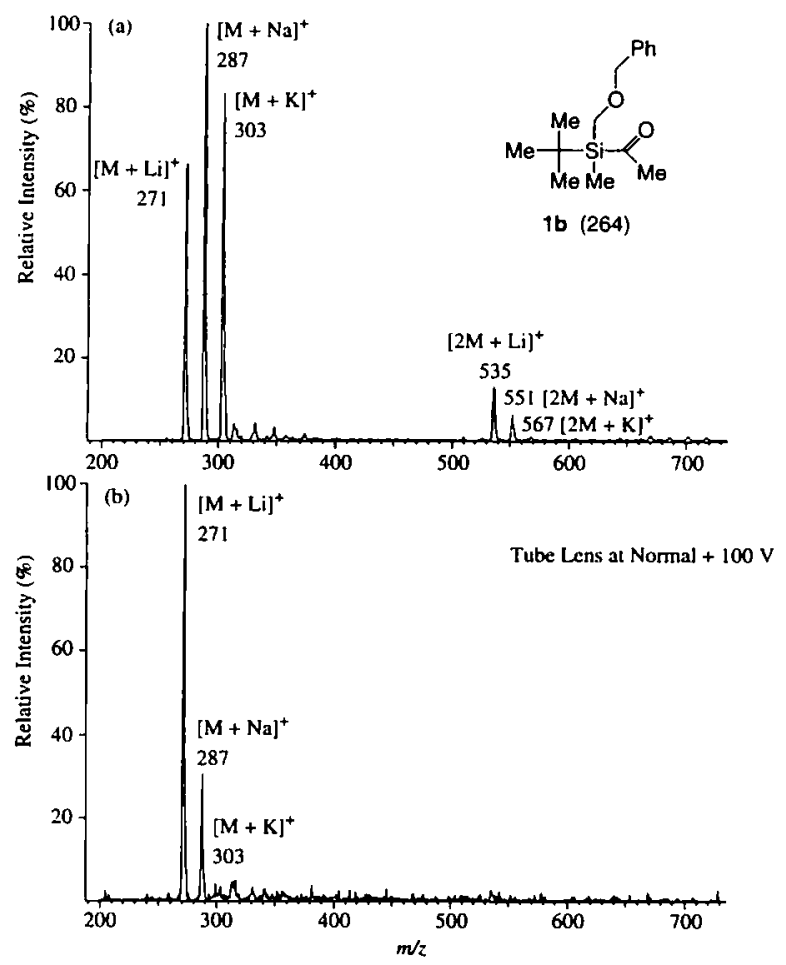

Figure 2. ESI mass spectra of $\mathbf{1 b}(0.1 \mathrm{~mm})$ applied in methanol/Lil/NaI/KI (each $10 \mathrm{~mm}$ ). (a) Tube lens at normal; (b) tube lens at normal $+100 \mathrm{~V}$ (tandem mass spectrometry-type conditions). tively obtained, however, with a tandem mass spectrometry-type experiment, where the relative stabilities of the complexes in the gas phase are examined. In fact, when the potential at the tube lens was increased by $100 \mathrm{~V}$-an experimental setup that gives rise to energy transfer to the ions in the gas phase and hence leads to secondary fragmentation as in a tandem mass spectrometry experiment ${ }^{\prime}$ - the expected order of stabilities of the acylsilane-cation complexes, $\left(\mathrm{S}_{[\mathrm{M}+\mathrm{Li}]^{+}}>\right.$ $S_{[M+N a]^{+}}>S_{[M+K]^{+}}$, is observed. The fragmentation of the $[\mathrm{M}+\mathrm{K}]^{+}$ions was found to be dominant over the decomposition of the $[\mathrm{M}+\mathrm{Na}]^{+}$ions, which, in turn, decompose more readily than the $\left[\mathrm{M}+\mathrm{Li}^{+}\right]^{+}$complexes. This is readily recognized in Figure $2 b$, where the highest abundance ion is found at $m / z 271$, which corresponds to the $[\mathrm{M}+\mathrm{Li}]^{+}$ion, and where the signals at $m / z 287$ for the $[\mathrm{M}+\mathrm{K}]^{+}$ion is negligible in intensity.

\section{Relative Stabilities of Acylsilane Alkali Complexes with Different Acylsilanes}

To investigate whether a relationship exists between relative ESI-MS responses (proposed to afford qualitatively relative complex concentrations in solution) and stereoselectivities of chelate-controlled addition reactions to different chiral alkoxymethyl-substituted acylsilanes (assumed to correlate with the relative complex stabilities), the mass spectrometric behavior of mixtures of the four acylsilanes $1 \mathbf{a}-\mathbf{d}$ in the presence of a single kind of metal cation was investigated. In such an experiment, and presupposing equal desolvation of the cations for all complexes, the relative concentrations of the acylsilane-alkali complexes should correspond to the respective relative complex stabilities and allow a direct correlation of stereoselectivity and ion response.

Because the occurrence of cluster ions, which are formed when acylsilanes are introduced into the ESIMS in methanolic solution, was regarded as disadvantageous, and because a rather slow but still bothersome decomposition of the acylsilanes, particularly the benzoylsilanes $\mathbf{1 b}$ and $\mathbf{1 d}$, was found in methanol [22], the solvent was exchanged for acetonitrile. Both problems - the cluster formation and the decomposition of the sample molecules-were overcome simultaneously by using this solute. Solely the desired [M + alkali] ${ }^{+}$ ions, and no other particles, were detected in the mass spectrometer, even when aged solutions or solutions that contained excess alkali salts were used.

When equimolar amounts of the four acylsilanes $\mathbf{1 a}-\mathbf{d}$ were dissolved in acetonitrile and brought into the ESI-MS (two by two or all four compounds together), the relative ion responses for $\left[1 a+a^{2} k a l i\right]^{+}$,

\footnotetext{
${ }^{1}$ ESI-MS investigations with polyamines have shown that almost equal spectra could be obtained by tandem mass spectrometry experiments (with argon as the collision gas) or by increased tube lens voltage (Bigler, L.; Hesse, M., unpublished results).
} 
$\left[1 \mathbf{b}+\right.$ alkali $^{+},\left[1 \mathrm{c}+\right.$ alkali $^{+}$, and $\left[1 \mathrm{~d}+\right.$ alkali $^{+}$were determined to be approximately 100:20:90:15 for the sodium complexes (cf. Figure 3a) or 100:70:98:55 for the lithium complexes (cf. Figure $3 \mathrm{~b}$ ). (The results of the direct comparison of all four compounds visualized with the two spectra in Figure 3 are consistent within an error of approximately $\pm 5 \%$ with the results of the two-by-two comparisons.) The relative ion responses for both cations, even though not equally pronounced with $\mathrm{Li}^{+}$, follow qualitatively the same course.

\section{Correlation of Stereoselectivity and Ion Response}

From the overlaid plots in Figure $3 b$, which visualizes the diastereoisomeric excesses (de; cf. Table 1 with scheme) of the chelate-controlled butyl lithium or butyl magnesium bromide additions to the respective compounds $1 \mathrm{a}-\mathrm{d}){ }_{1}{ }^{2}$ a rough correlation of the relative ion responses and the relative stereoselectivities of the addition reactions can be recognized. Distinctively more abundant ion responses and, matched with these signal intensities, higher diastereoisomeric excesses are found for the 2-(methoxyethoxy)methyl-substituted

${ }^{2}$ We are aware that the results of alkali cationizations and reactions that involve magnesium species cannot be compared directly. Because the reactions of lithium- or magnesium-organometallic species follow approximately the same course, however, the stereoselectivities obtained with the Grignard reagents are presented for illustrative reasons as well.

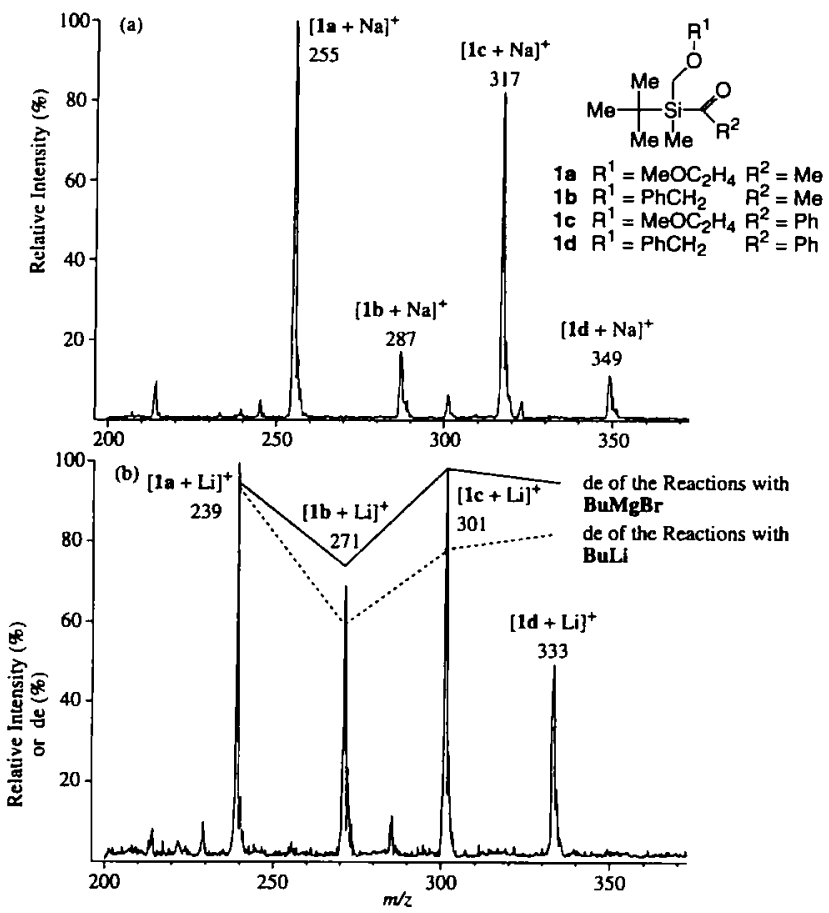

Figure 3. ESI mass spectra of $1 \mathbf{a}-\mathbf{d}$ (each $0.1 \mathrm{~mm}$ ) applied (a) in $1-\mathrm{mM} \mathrm{NaI} /$ acetonitrile or (b) in 10-mM Lil/acetonitrile. The plot of diastereoisomeric excesses (de) obtained by 1,4-addition of $\mathrm{BuMgBr}$ or of $\mathrm{BuLi}$ to the carbonyl groups of the respective acylsilanes is overlaid in (b).
Table 1. Diastereoselectivities of the reactions of acylsilanes $1 \mathbf{a}-\mathbf{d}$ with butyl lithium and butyl magnesium bromide in ether at $-100^{\circ} \mathrm{C}$.
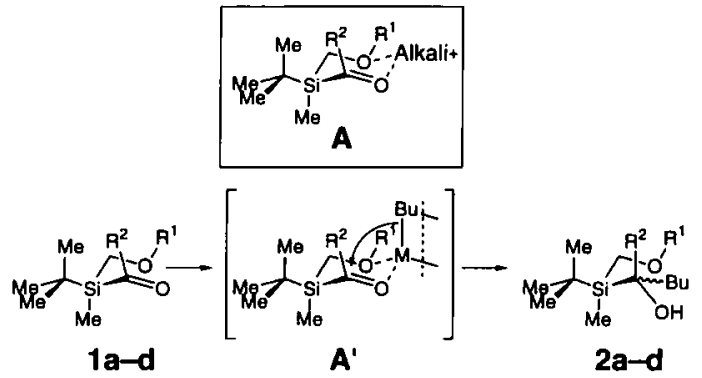

\begin{tabular}{|c|c|c|c|c|c|c|}
\hline \multicolumn{3}{|c|}{ Substrate } & \multirow{2}{*}{$\begin{array}{l}\text { Reagent } \\
\text { BuM }\end{array}$} & \multicolumn{3}{|c|}{ Addition Product } \\
\hline No. & $\mathrm{R}^{\mathrm{l}}$ & $\mathrm{R}^{2}$ & & No. & $\begin{array}{l}\text { Yield } \\
{[\%]}\end{array}$ & $\begin{array}{l}\text { de } \\
{[\%]}\end{array}$ \\
\hline 1a & $\mathrm{MeOC}_{2} \mathrm{H}_{4}$ & $\mathrm{Me}$ & BuLi & $2 a$ & 60 & 95 \\
\hline $\mathbf{I b}$ & $\mathrm{PhCH}_{2}$ & $\mathrm{Me}$ & BuLi & $\mathbf{z b}$ & 56 & 60 \\
\hline $1 c$ & $\mathrm{MeOC}_{2} \mathrm{H}_{4}$ & $\mathrm{Ph}$ & BuLi & $2 c$ & 57 & 78 \\
\hline Id & $\mathrm{PhCH}_{2}$ & $\mathrm{Ph}$ & BuLi & $2 d$ & 40 & 83 \\
\hline $1 \mathbf{a}$ & $\mathrm{MeOC}_{2} \mathrm{H}_{4}$ & Me & BuMgBr & $2 \mathbf{a}$ & 68 & 96 \\
\hline $\mathbf{l b}$ & $\mathrm{PhCH}_{2}$ & Me & BuMgBr & $\mathbf{b}$ & 60 & 72 \\
\hline 1c & $\mathrm{MeOC}_{2} \mathrm{H}_{4}$ & $\mathrm{Ph}$ & BuMgBr & $2 c$ & 42 & 99 \\
\hline 1d & $\mathrm{PhCH}_{2}$ & $\mathbf{P h}$ & BuMgBr & 2d & 53 & 94 \\
\hline
\end{tabular}

acylsilanes $1 \mathrm{a}$ and $1 \mathrm{c}$ as compared to the benzyloxymethyl-substituted analogs $\mathbf{1 b}$ and $\mathbf{1 d}$. This observation not only supports our earlier assumption of the higher affinity of the acylsilanes $\mathbf{1 a}$ and $1 \mathrm{c}$ toward alkali cations compared to the corresponding compounds $\mathbf{1 b}$ and $\mathbf{1 d}$ (due to the additional oxygen atoms in the alkoxy substituents at silicon in 1a and 1c), but also corroborates our hypothesis that the stereoselectivities of the addition reactions to acylsilanes of type 1 parallel their capability to coordinate a Lewis acid.

Contrary to the stereochemical results obtained in the addition reactions, however, the relative ion responses of the acetylsilane complexes $\left[1 \mathrm{a}+\mathrm{Li}^{+}\right.$and $[1 \mathbf{b}+\mathrm{Li}]^{+}$as compared to those of the respective benzoylsilane complexes $\left[1 \mathrm{c}+\mathrm{Li}^{+}\right.$and $[1 \mathrm{~d}+\mathrm{Li}]^{+}$are more ample. However, in contrast to the foregoing comparisons of the 2-(methoxyethoxy)methyl-substituted acylsilanes with the benzyloxy-substituted analogs, the differences of the relative ion abundances observed by comparing these closely related compounds, which do not differ in the number of heteroatoms crucial for cation complexation, are less pronounced. Accordingly, the transference of ESI-MS results to wet-chemical expectations could be anticipated a priori to be less reliable. Acceptance, though, of the relative ion responses as a measure for relative complex concentrations in solution (thermodynamic equilibrium), which has not been proven unambiguously yet, allows the discrepancies of the ESI-MS and the 
stereochemical results to be explained as follows:

1. The species analyzed in the ESI-MS experiments and the particles proposed as intermediates in the addition reactions are not identical. In one case alkali cation complexes of type $\mathbf{A}$, dissolved in acetonitrile, are studied, and in the other case complexes of organometallic substrates of type $\mathbf{A}^{\prime}$ in diethyl ether solutions are regarded as the important structures. It is rational to accept that the different species in the different environments can have different relative stabilities, too.

2. It has not been ascertained explicitly yet, whether the diastereoselectivities of the addition reactions to the acylsilanes $\mathbf{1 a}-\mathbf{d}$ are in fact directly correlated with relative complex stabilities of the proposed intermediates. The diastereoselectivities also can express a kinetic situation where the rate of the formation of an acylsilane-metal complex is of central importance rather than its stability. For compounds that differ strongly in their complexing capabilities, kinetics are expected to favor the same products as thermodynamics would. In cases, however, where the differences in complexing abilities are not too distinct, a reliable prediction of the kinetic preference of a particular complexing agent by a cation is not trivial. It is conceivable that when acetylsilanes are compared with benzoylsilanes, the kinetic (stereochemical results) and the thermodynamic preferences of a complex (ESI-MS results) can be opposite.

\section{Conclusions}

Even though a rough correlation of ion response in ESI-MS with stereoselectivity of a chelate-controlled reaction could be found, the ESI-MS is still far from being a reliable tool to predict chemical behavior-at least as long as the investigated systems are as far related to one another as they are in our case. However, the ESI-MS results still allow-even in such nonoptimal cases-a coarse estimation of chemical behavior: when the differences of the peak intensities in the ESI-MS are distinct enough, a rather good correlation with the chemical behavior was found. Only in the cases where almost equal ion responses are observed, the correlation failed. Equal or almost equal ion response can indicate that, in these cases, the reactivity differences are also rather small and adequately susceptible toward changes in the environment, such as differences in the solvent or the aggregation state of the species involved.

\section{Acknowledgments}

We thank the Swiss National Science Foundation for financial support and Professor Dr. M. Hesse for providing laboratory space, equipment, and regular occasions for professional discussions.

\section{References}

1. Bruins, A. P.; Covey, T. R.; Henion, J. D. In Proceedings of the 34th Annual Conference on Mass Spectrometry and Allied Topics; Cincinnati, 1986.

2. Bruins, A. P.; Covey, T. R.; Henion, J. D. Anal. Chem. 1987, $59,2642$.

3. Covey, T. R.; Bonner, R. F.; Shushan, B. I.; Henion, J. D. Rapid Commun. Mass Spectrom. 1988, 2, 249.

4. Cook, K. D. Mass Spectrom. Rev. 1986, 5, 467.

5. Dole, M.; Mack, L. L.; Hines, R. L.; Mobley, R. C.; Ferguson, L. D.; Alice, M. B. I. Chem. Phys. 1968, 49, 2240.

6. Schmelzeisen-Redeker, G.; Bütfering, L.; Röllgen, F. W. Int. J. Mass Spectrom. Ion. Processes 1989, 90, 139.

7. Fenn, J. B.; Mann, M.; Meng, C. K.; Wong, S. F.; Whitehouse, G. M. Mass Spectrom. Rev. 1990, 9, 37.

8. Smith, R. D.; Loo, J. A.; Edmonds, C. G.; Barinaga, C. J.; Udseth, H. R. Anal. Chem. 1990, 62, 882.

9. Ikonomou, M. G.; Blades, A. T.; Kebarle, P. Anal. Chem. 1991, 63, 1989.

10. Lüttgens, U.; Röllgen, F. W.; Cook, K. D. In Methods and Mechanisms for Producing lons from Large Molecules; Standing, K. G.; Ens, W., Eds.; Plenum: New York, 1991; p 185.

11. Siu, K. W. M.; Guevremont, R.; Le Blanc, J. C. Y.; O'Brien, R. T.; Berman, S. S. Org. Mass Spectrom. 1993, 28, 579.

12. Ashton, D. S.; Beddell, C. R.; Cooper, D. J.; Green, B. N.; Oliver, R. W. A. Org. Mass Spectrom. 1993, $28,721$.

13. Kebarle, P.; Tang, L. Anal. Chem. 1993, 65, 972.

14. Iribarne, J. V.; Thomson, B. A. J. Chem. Phys. 1975, 64, 2287.

15. Thomson, B. A.; Iribarne, J. V. J. Chem. Phys. 1979, 71, 4451.

16. Thomson, B. A.; Iribarne, J. V.; Dziedzic, P. J. Anal. Chem. 1982, 54, 2219.

17. Röllgen, F. W.; Bramer-Weger, E.; Bütfering, L. J. Phys. 1987, 48, C6.

18. Röllgen, F. W.; Nehring, H.; Giessmann, U. In Ion Formation from Organic Solids (IFOS V); Hedin, A.; Sundqvist, B. U. R.; Benninghoven, A., Eds.; Wiley: Chichester, 1989.

19. Guevremont, R.; Siu, K. W. M.; Le Blanc, J. C. Y.; Berman, S. S. J. Am. Soc. Mass Spectrom. 1992, 3, 216.

20. Cheng, Z. L.; Siu, K. W. M.; Guevremont, R.; Berman, S. S. J. Am. Soc. Mass Spectrom. 1992, 3, 281.

21. Chapeaurouge, A.; Bienz, S. Helv. Chim. Acta 1993, 76, 1876.

22. Brook, A. G.; Bassindale, A. R. In Rearrangements in Ground and Excited States; de Mayo, P., Ed.; Academic Press: New York, 1980; Vol. 42-2, p 149. 